\title{
Locally Advanced Thyroid Cancer, series of cases, January 2003 - December 2013
}

\author{
Medrano F1*, Morin $\mathrm{L}^{2}$, Palacios $\mathrm{R}^{3}$ and Torres $\mathrm{E}^{4}$ \\ ${ }^{1}$ Oncologic Program, Salud Integral Hospital, Nicaragua \\ 2ENT MD, Salud Integral Hospital, Nicaragua \\ 3Pathologist MD, Salud Integral Hospital, Nicaragua \\ ${ }^{4}$ Research Health Center, Medicine School, León University, Spain
}

\section{Mini Review}

Volume 2 Issue 1

Received Date: October 27, 2017

Published Date: January 18, 2018

*Corresponding author: Francisco Jose Medrano Sanchez, Oncologic Program, Salud Integral Hospital, Managua, Nicaragua; Tel: 505-8880-5968; Email: fmedranos@hotmail.com

\section{Abstract}

Objective: The aim of this study is to describe the patients characteristics, histophatologic type, prognosis factor, Shin's classification and treatment in patients with locally advance thyroid cancer.

Methods: Descriptive study. Series of case: 10 patients with diagnosis thyroid cancer locally advance. AMES was used as the prognosis factor system, Shin's classification to locally advance. The univariatereview was realized with frequency and percentage.

Results: 10 patients with locally advance thyroid cancer, 6 male and 4 female, the age range was between 42 and 86 years old, the media was 66.1 years old.

Keywords: Thyroid; Radiotherapy; Prognostic

\section{Introduction}

Locally advance thyroid cancer, represent between 15 $20 \%$ of them [1]. The most frequent presentation is a neck gross tumor. The fatal clinical debut is a patient with stridor and asfixia when arrive to the emergency room [25]. The multimodal treatment with radiotherapy and chemotherapy is still in controversy. The overall survival is uncertain as shown in Figure $1 \& 2$.

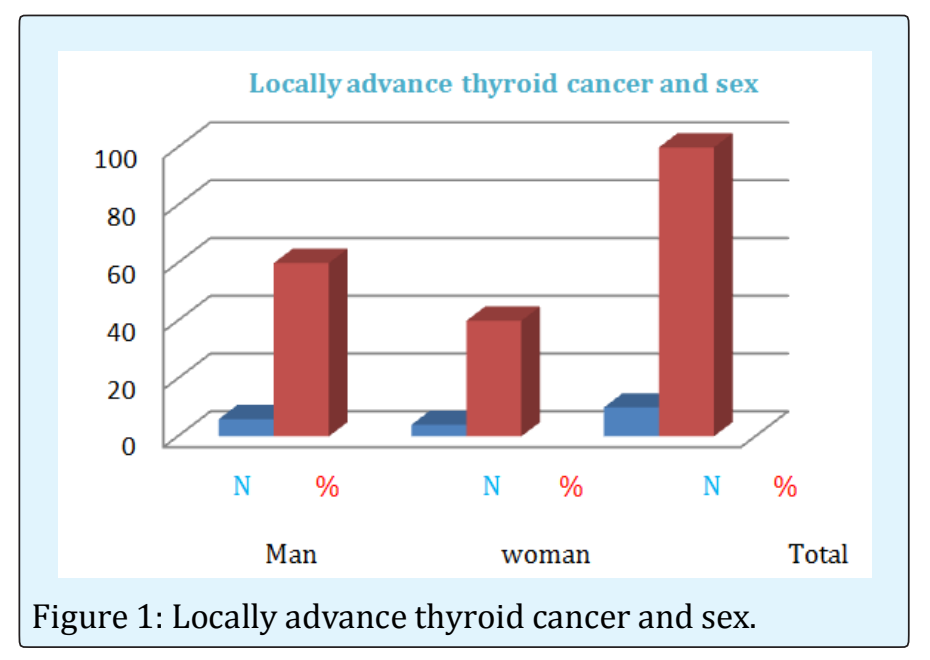




\section{Open Access Journal of Endocrinology}

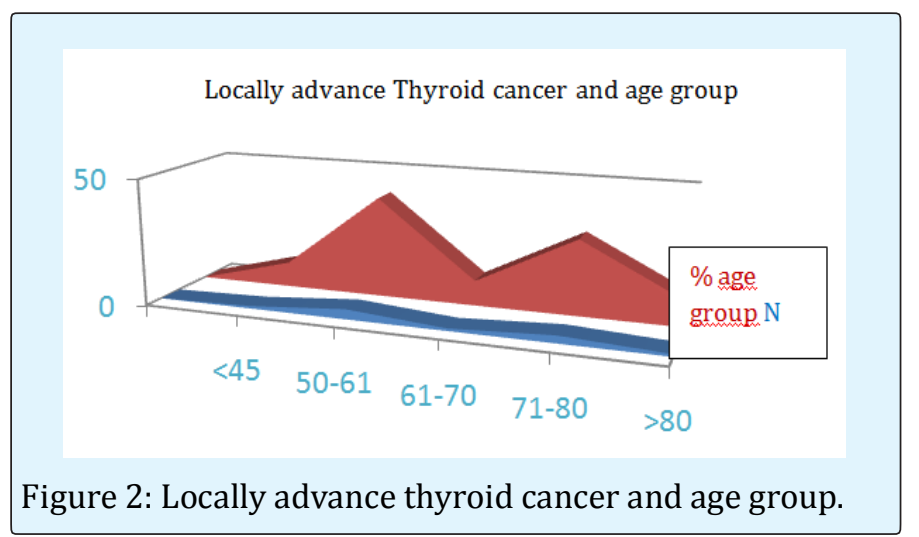

The histophatologic type was papillary cancer $70 \%$, Anaplastic cancer $20 \%$ and Follicular cancer $10 \%$ in Figure 3.

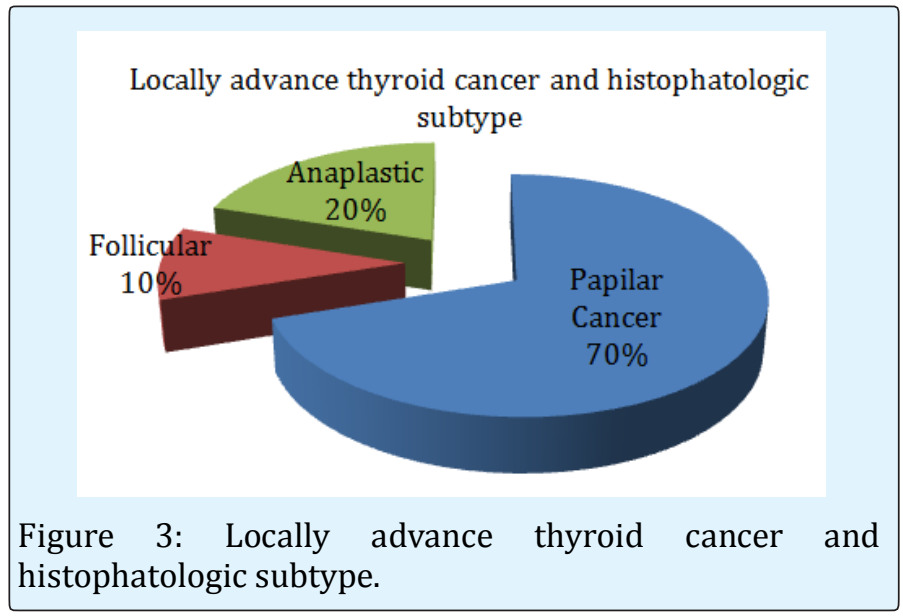

With AMES prognostic factor $90 \%$ were patients with more than 45 years old, $40 \%$ with metastasis, 3 with lung metastasis and one patient with spinal metastasis. $100 \%$ patients with extra glandular extension and gross tumor major $4 \mathrm{~cm}[6,7]$ (Figure 4).

Locally advance thyroid cancer and AMES prognostic factor



Figure 4: Locally advance thyroid cancer and AMES prognostic factor.

70\% were III Stage, 30\% II Stage Shin's classification [8].
The clinic presentation was neck gross tumor, in all patients, disphonia $50 \%$, stridor $40 \%$, hoarseness $50 \%$ and disphagia 30\% in Figure 5A \& 5B.

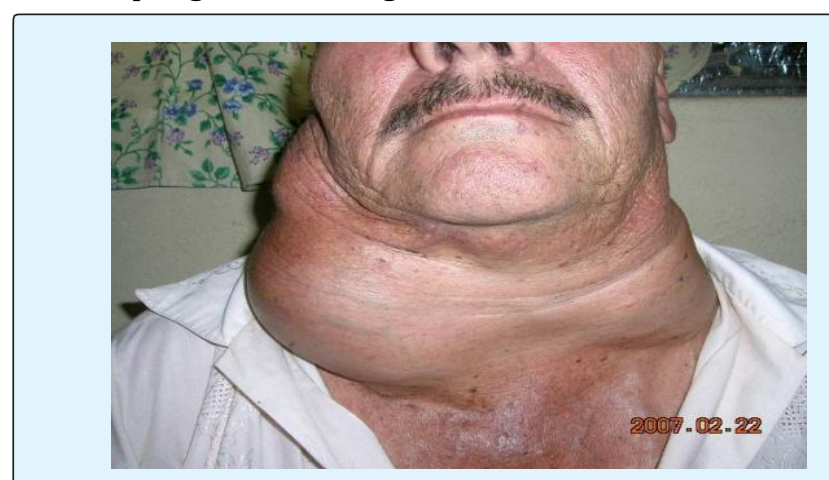

Figure 5A: 58 year old man with gross anterior mass in the neck.

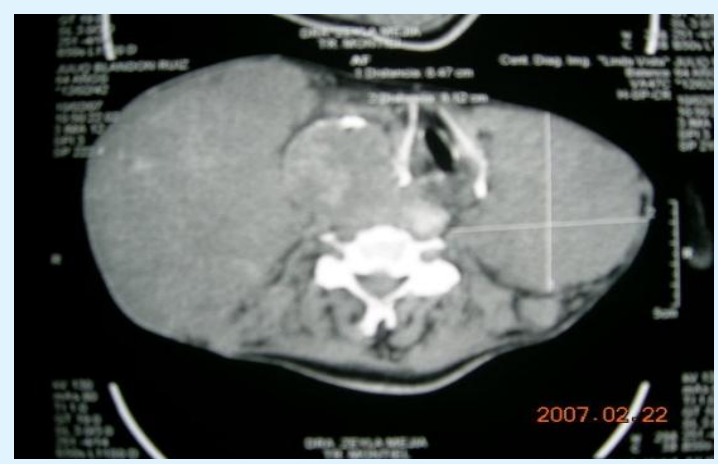

Figure 5B: CT scan show thyroid cancer invading right larynx.

The treatment was Total thyroidectomy plus shave laryngotracheal, plus left radical neck dissection, plus radiotherapy one patient. In Figure 6 Total thyroidectomy plus I-131 plus radiotherapy one patient, total thyroidectomy plus debulking, plus radiotherapy one patient, total thyroidectomy plus, radiotherapy one patient. Radiotherapy one patient, and two patients refused the treatment in Figure 6,7 [9-15].

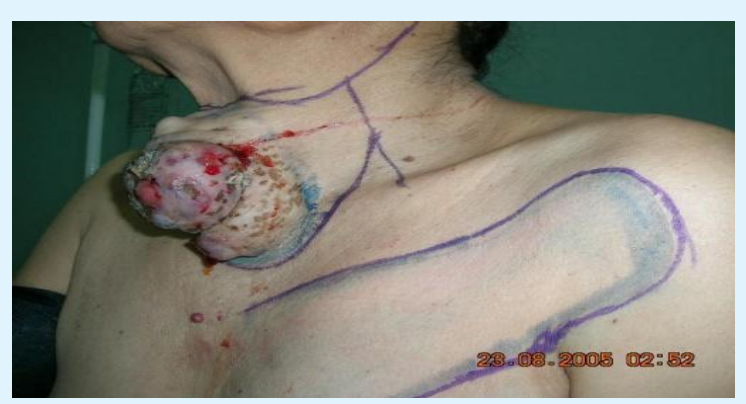

Figure 6: 59 years old woman Total thyroidectomy plus Shave laryngotracheal plus Reconstruction. 


\section{Open Access Journal of Endocrinology}



In Figure 8, 3 patients tracheotomy palliative 30\%.


\section{Conclusion}

Locally advance thyroid cancer is the most frequent in the elder patients, gender male and papillary histophatologic type, with the majority of prognostic factor's high risk and tracheal and larynx wall invasion, still is (in fact) multimodal treatment and controversial treatment.

\section{References}

1. Shindo ML, Caruana SM, Kandil E, McCaffrey JC, Orloff LA, et al. (2014) Management of invasive welldifferentiated thyroid cancer: an American Head and Neck Society consensus statement. AHNS consensus statement. Head Neck 36(10): 1379-1390.

2. Honings J, Stephen AE, Marres HA, Gaissert HA (2010) The management of thyroid carcinoma invading the larynx or trachea. Laryngoscope 120(4): 682-689.

3. Lee YS, Chung WY, Chang HS, Park CS (2010) Treatment locally advance thyroid cancer invading great vessel. Inter actcardiovascular Thoracic Surgery 10(6): 1039-1041.

4. A Shaha (2008) Air way management in anaplastic thyroid cancer. The Laryngoscope 118(7): 11951198.

5. A Shaha (2008) Revision of thyroid Surgery, technical considerations. Otolaryngol Clin N Am 41(6): 11691183.

6. G Randolph, Kamani D (2006) Preoperative Laryngoscopy in patients to detection of invasive thyroid cancer. Surgery 139(3): 357-362.

7. McCaffrey JC (2006) The Aerodigestive tract invasion by well differentiate thyroid cancer. The Laryngoscope 116(1): 1-11.

8. Shin DH, Mark EJ, Suen HC, Grillo HC (1993) athologic staging of papillary carcinoma of the thyroid with air way invasion. Hum Pathol 24(8): 866-870.

9. Lee N, Tuttle M (2006) The Role of external beam radiotherapy in the thyroid cancer. Endo Releat Cancer 13(4): 971-977.

10. A Shaha, Patel KN (2002) Locally advance thyroid cancer. Head and neck surgery 13(2): 112-116. 


\section{Open Access Journal of Endocrinology}

11. Kowalsky LP, Filho JG (2002) Results of the treatment of locally invasive thyroid carcinoma. Head and Neck 24: 340-344.

12. Kim KH, Sung MW, Chang KH, Kang BS (2000) Therapeutic dilemma in the management of thyroid cancer with laryngotracheal involvement. Otolarngol head and neck surgery 122(5): 763-767.

13. Czaja J, McCaffrey TV (1997) Surgical management of laryngotracheal invasion of well differentiated thyroid cancer. Arch Otolarngol head and neck surg 123(5): 484-490.

14. Namori $H$ (1990) The incidence of laryngotracheal invasion and esophageal invasion by well differentiated thyroid carcinoma. J Surg Oncol 44: 78.

15. Shah JP, Cody III HS (1981) locally invasive well differentiated thyroid cancer, 22 years experience of Memorial Sloan Kaettering cancer centers. Am J Surg 142(4): 480-483. 